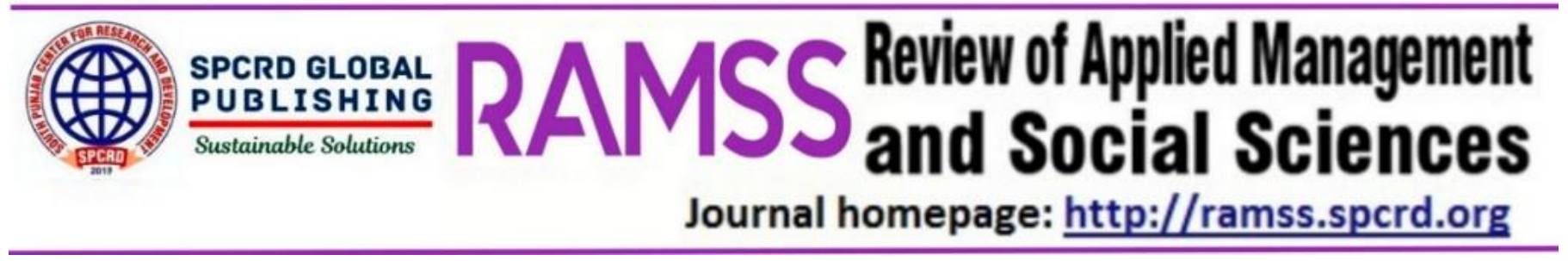

\title{
Stock Price Natural Disaster: A Case of Pakistan Cement Sector
}

\author{
${ }^{a}$ Muhammad Hafeez Ullah, bShahzad Akhtar, ${ }^{\mathrm{c}}$ Haroon Hussain, ${ }^{\mathrm{d}}$ Hina Ismail \\ aphDRiphah international university, Islamabad, Pakistan:hafeezyasiroo7@gmail.com \\ bLecturer, Institute of Management Science BZU, Multan, drshahzadakhtar@bzu.edu.pk \\ cAssistant Professor, Noon Business School, Multan, haroon.hussain@uos.edu.pk \\ dLecturer, National University of Modern Languages, Multan Campus: hina.ismail@numl.edu.pk \\ Corresponding author’s email address: drshahzadakhtar@bzu.edu.pk
}

\begin{tabular}{ll}
\hline ARTICLE DETAILS & \multicolumn{1}{c}{ ABSTRACT } \\
\hline $\begin{array}{l}\text { History: } \\
\text { Accepted: } 10 \text { June } 2019\end{array}$ & $\begin{array}{l}\text { Current The aim of current study is to investigate the impact of natural disaster } \\
\text { on stock market in case cement sector of Pakistan. The approach of current study } \\
\text { Available online: } 30 \text { June } \\
\text { is to explore the effect of natural disaster on change in stock price in a given } \\
\text { index. The study has used event study methodology to explore the relationship. }\end{array}$ \\
$\begin{array}{ll}\text { Keywords: } & \text { Stock markets react differently from certain natural disaster events. The natural } \\
\text { Stock Markets Share Price, } & \text { events, flood, earthquake, extreme temperature, land sliding, has significant effect } \\
\text { on stock prices and its effect on share price volatility. All evidence provide from } \\
\text { Study, Abnormal Returns }\end{array}$ & Pakistan stock exchange.
\end{tabular}

JEL Classification:

(C) 2019 The authors. Published by SPCRD Global publishing. This is an open

E30, E31, E39 access article under the Creative Commons Attribution-NonCommercial 4.0

DOI:

10.47067/ramss.v2i1.13

\section{Introduction}

The intention of this study is to discover the impact of natural disaster or rare event on stock market. This is long standing problem in macroeconomic and financial economic, why aggregate stock market returns have volatility? Question elevated by (Emil Sriwardane, 2015). Rietz and thomsan (1988) and barro (2006) argued that rare events disturb the stock markets. The stock market movement have been deeply studied by many researchers (e.g. cutler et al. , 1989; fair, 2002; Kim, 2003).

Nakamura et al. (2013) the few natural unexpected events can affect the performance of a stock market even if time of the disaster is old and even if there are economic recoveries in the market. On contrary, there are many authors who suggest that natural disasters have no relationship with equity based models, the reason can be that probability of any natural disaster is unknown (Julliard and Ghosh (2012), Backus et al. (2011), Chen et al. (2015)) 
Pakistan is also one of the currently where natural disasters has effect on local market for example the earth quake of 2005 , flood of 2007,2010 badly effect the economic situation of country (NDMA, 2010). Therefore, stability in economic development is important from all aspects (Shaikh \&Memon, 2011). It is important to understand how event of natural disaster might effect of return of many stocks in Pakistan Stock Exchange (PSE), which is the only 100 index market of the country. The study contributes in novelty as this study has used larger time frame and considered multiple events i.e. flood, land sliding, storms, earth quakes, heat waves. Therefore, the study has used multiple event windows to study the impact of natural disaster on stock price of firms listed in PSE. Furthermore, it also observes the impact of favorable and unfavorable events individually. Hence the impact of any natural event is observed only on after and before 11 days window.

The effort of this study is to investigate the relational impact of natural disaster (flood, storm, earth quack, high temperature) that have relationship with stock returns. The factors introduced many previous authors the factors which have announced impact such as interest rate, foreign exchange, policy of payout and some more. Similarly, other events which are political, or any event which can product instability (Suleiman, 2012). Many studies on natural unexpected events explain that these events affect stock markets.

\section{Literature Review}

Skid more and Toya(2002) explain the effect of natural disasters in normality felt first in the loss of capital stocks markets, according to past studies financial impact of natural disaster have tended to employ a single event study. Disaster is an event that occurs in brutal catastrophe and suddenly (Dictionary, 2011). Disaster can also be described as a national economic catastrophe or leading the catastrophic world. Catastrophe can be categories as "natural catastrophe" and "man-made". According to Swiss Re (2011), natural forces will cause a natural catastrophe event. This event usually causes a large number of damage and losses that cover huge areas. Geok Hui (2012) there is numerous types of natural disasters including floods, tsunami, earthquake, hurricane, tornado, volcanic eruption and others.

Natural disaster are becoming more repetition in nature and destructive in effect, it persuaded the researcher to increase the understanding and impact of these event on economics and real shock it can produce which could be vital in effect. Hence, there is multiple researches available on the effect of natural disaster on growth of economies (Cavallo and Noy, 2011). For example, One of the research defined that earth quake has negative relationship with economic growth (Fomby et al. 2013).

To discuss the relationship of natural disaster with stock market, Worthington and Valadkhani (2004) applied ARMA model to investigate the impact of forty two natural event such as storms, floods, earthquakes from 1982 to Jan 1st 2002. The results of the study revealed that cyclones and earth quakes have significant relationship with prices in stock market in comparison to storms and floods. in another study, Worthington and Valadkhani (2005) document the comparison of natural disaster and terrorist event on stock market. The author applies Box and Tiao analysis on ten different sectors of market. The results revealed that sectors such as monetary services and material sectors were more sensitive to the events in comparison to other sectors of the economy.

One of the most significant event occurred was a terrorist attacks of 9-11, which not only effected the US market but it also effect the price of around the world. Similarly, Shelor et al (1990) 
studied the effect of earth quake of California on five value creating deals of real estate. The study revealed that the stock return has negative relationship with earthquake event of California specifically in fun's stock return operating in areas of earth quake. Hence there are many studies available in previous literature of different countries which defines that any news of natural disaster event can affect the prices in stock market of different sectors.

The variation of natural disaster is very large for emerging markets specially markets established on small islands are much susceptible to the event of nature. For example, the cost paid by the five largest economies of the world due to natural disasters between years 1985 to 2015 is $0.4 \%$ if the GDP, while this ratio which is $7.7 \%$ of GDP is very high for five smallest economies of the world. There are several factors that affect the economic cost of natural disasters ( Cavallo \&Noy (2010).

The key factor which defines the economic cost of natural event is geography or geographical location of a country and types of natural disasters usually hit to that region. For example, multiple river basin and larger flood plain of a country increases the chances of flood. Similarly, Hurricane susceptible areas increase the chances of storms damages. For example, the small islands of Caribbean oceans and pacific ocean regions are very much vulnerable to such kind of events.

Moreover, size of the country also matters, smaller the size of the country greater the risk of country to pay economic price. Similarly, larger the area and population of the country larger the damage produced by the natural disaster, but can be smaller in economic cost as larger countries have more assets to pay the price. Hence, the larger countries have move capacity to absorb the shock of natural disaster in comparison to small countries as they have maximum asset to reduce the impact of natural disaster.

Taylor and Francis (2004) examine the financial costs natural disasters on economy. The results of the study revealed that productivity of the country is affected directly and indirectly by the natural disaster. Moreover, Albia Bertrand(1993) noticed that in all cased inflation is the factor which is not effect by natural disaster. and ramie(2013) investigated the effect of Tsunami event on world stock markets. The results presented by the study revealed that it had no significant impact on stock markets or it might be minimal impact it can produce. Ramiah (2013) noted that if 5 days after the events are taken in the window then the returns in the stock market are very minimal effected by the event. Hence, any significant impact on equity portfolios was no determined by the author.

\section{Methodology}

Since we are interested to investigate natural disaster event has an impact on stock markets, event study methodology has been adopted by following (Mackinlay, 1997). This approach is very vital in nature as it capture any abnormal return or residual produced in the price by explaining the underlying market efficiency hypothesis. While this fact has been better explained by Fama, (1969) that any change in price will be reflected immediately of an event.

To test the hypotheses secondary data has been used. It required three kinds of data, one about stock prices 2nd about cement sector while the other dataset about catastrophic events. Data about KSE stock returns and cement sector share prices has been obtained from Yahoo Finance. It consists of a cement sector all companies observations from 2012 to 2016(five year) and KSE stock return 2012 to 2016. Data about Catastrophic events has been obtained from website of data stream. The current study is taking event based on the extreme produce by the event due to extensive media exposure. Natural 
disaster events selected in this study and with further divided in to 4 type of occurrence. One is flood 2nd is land sliding 3 rd is extreme temperature and 4 th is earth quack and we consider natural disaster as negative event.

\section{Event Study Design}

The event window of any event will be from time o to 24 hours of the particular date. In in case the event is happened on a public holiday the very next of the event will be considered as event day. Moreover, for the sake of estimation 10 days prior and 1odays after the event has been taken. In order to be able to significant cumulative abnormal returns (CAR) for one sample period, the benchmark we selected those event that have more than 40 deaths. Hence our hypothesis testing framework.

Ho: $\mathrm{u}=\mathrm{CAR}(\mathrm{t} 1, \mathrm{t} 2)=\mathrm{o}$

Ho: $\mathrm{u}=\mathrm{CAR}(\mathrm{t} 1, \mathrm{t} 2)=\mathrm{o}$

The main idea of any event study is to capture the effect of any abnormal return of over all stock market due to event.. However, the current study is more interested in stock market indices. 1st off all we calculate the adjusted return of cement sector stock return and all indexes return, then we find the slope, standard error, R square, Intercept by using the excel formals, then find the expected return , then we find the abnormal returns by use the actual return minus expected return.

The calculation is:

$$
\mathrm{ERm}, \mathrm{t}=\mathrm{AORm}, \mathrm{t}-\mathrm{AVRm}
$$

Where ERm,t is the excess return for stock market index $m$ at time $t$, AORm,t is the actual observed market return for stock market index $m$ at time $t$ and AVRm is average of stock market index m's daily return in the estimations window. AVRm is computed from added the slope and intercept and multiply with event window.

In addition, the current study is also interested to draw relevant and overall inferences of an event, the observation of abnormal return must be included (Mackinlay 1997). The inclusion (i.e. CAR) will take on all natural disaster events in consideration. We defined CAR ( $\mathrm{t} 1, \mathrm{t} 2) \mathrm{m}$

We computed:

$$
\mathrm{CAR}(\mathrm{t} 1, \mathrm{t} 2) \mathrm{m}=\sum_{m=t_{1}}^{t 2} \bar{R}_{m, t}
$$

T stat applied before CARm that deviated from zero with equal to or less the -1.95 and equal to or more than +1.95 will designed as a significant impact. T statistics compute from division of abnormal return and standard error.

Result analysis 
Frame 1: flood

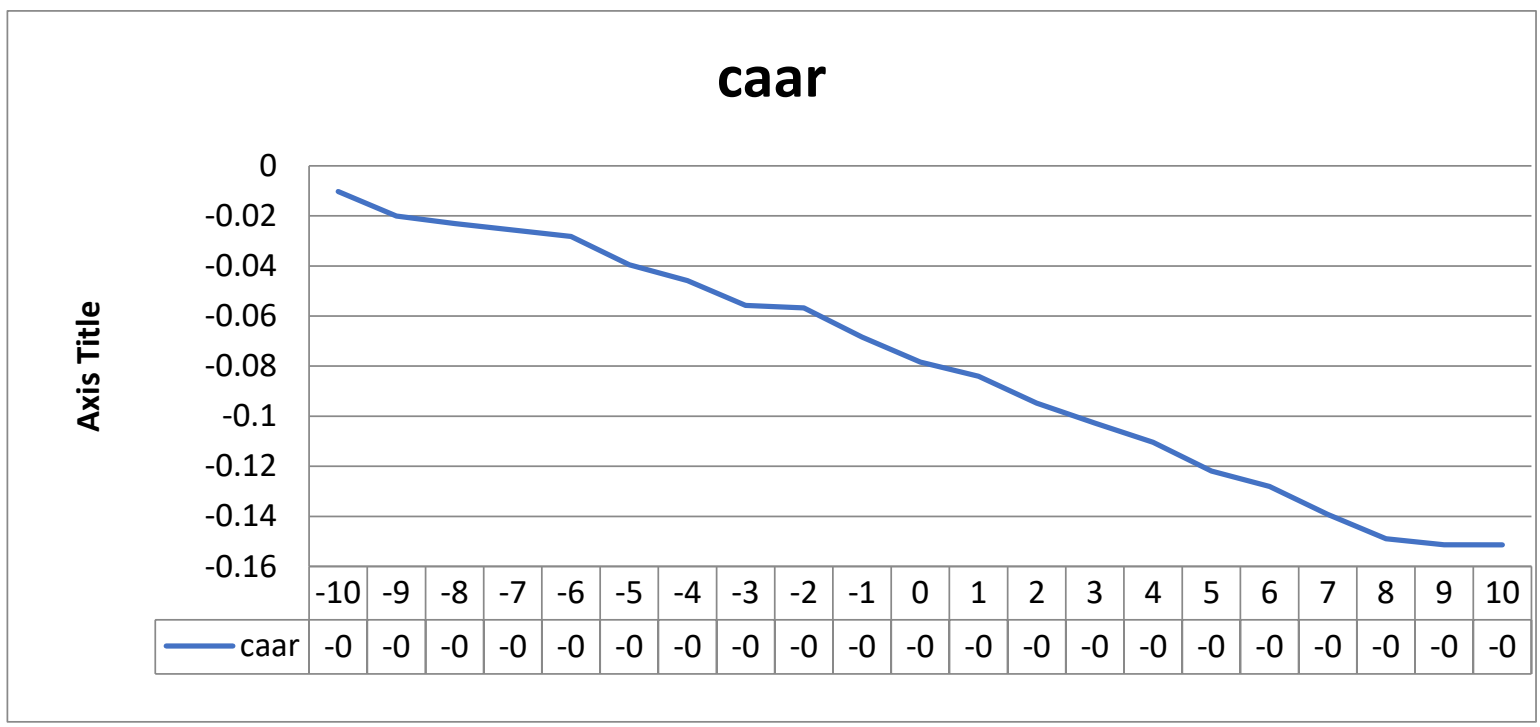

Flood show the negative curve in events days. Before event window the accumulated abnormal return is higher when day by day the trend goes down and stops on -.16. Trend show the effect of flood on stock returns is negative and significant related.

Frame 2: land sliding

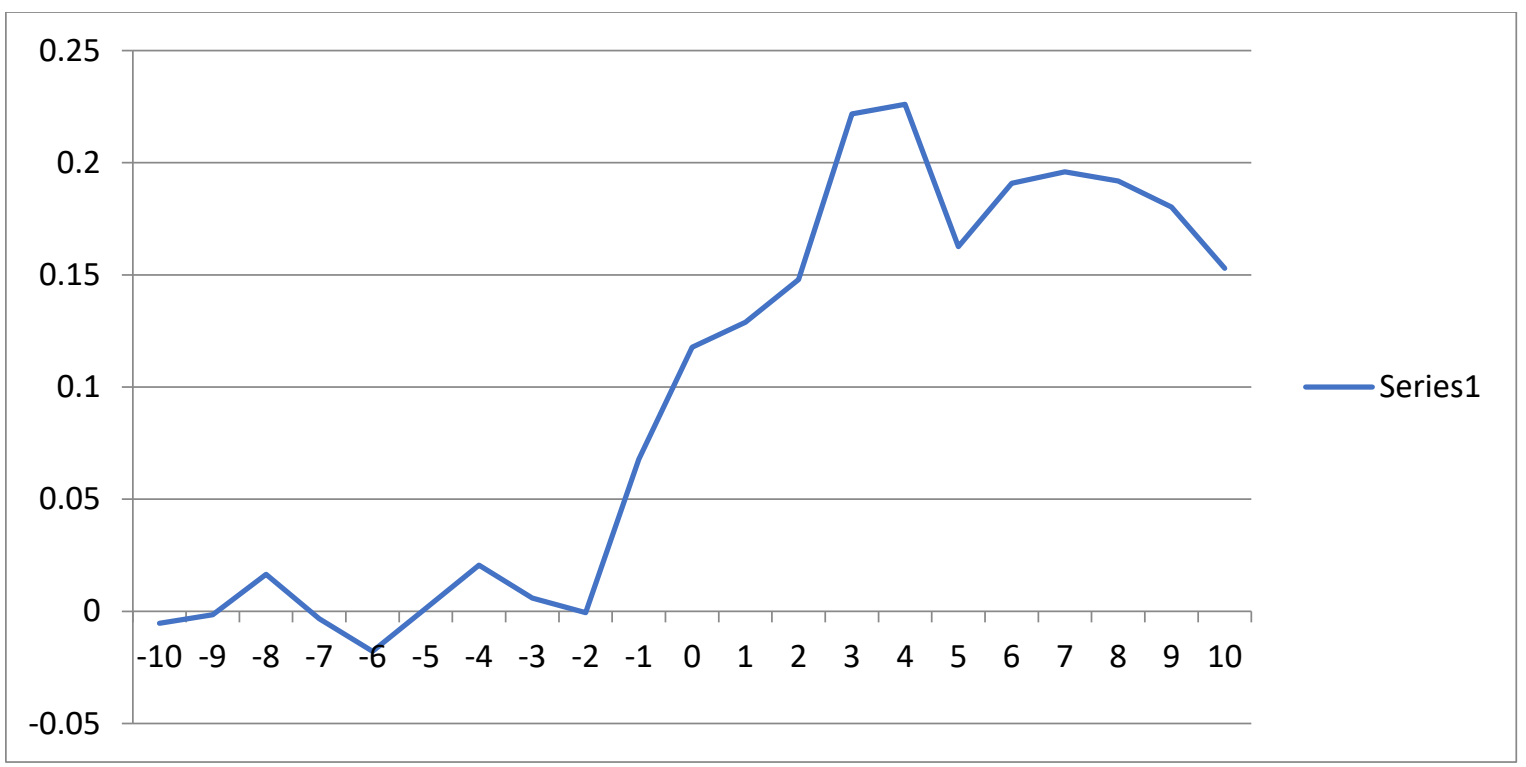

Before land sliding market is down and shows the negative average abnormal return but before event date trend going on positive after event day market goes higher before last day of event window the curve show negative slop but this is normal. So here curve show the positive but the land sliding does not affect the cement sector price or return.

Frame 3: Earth quack 


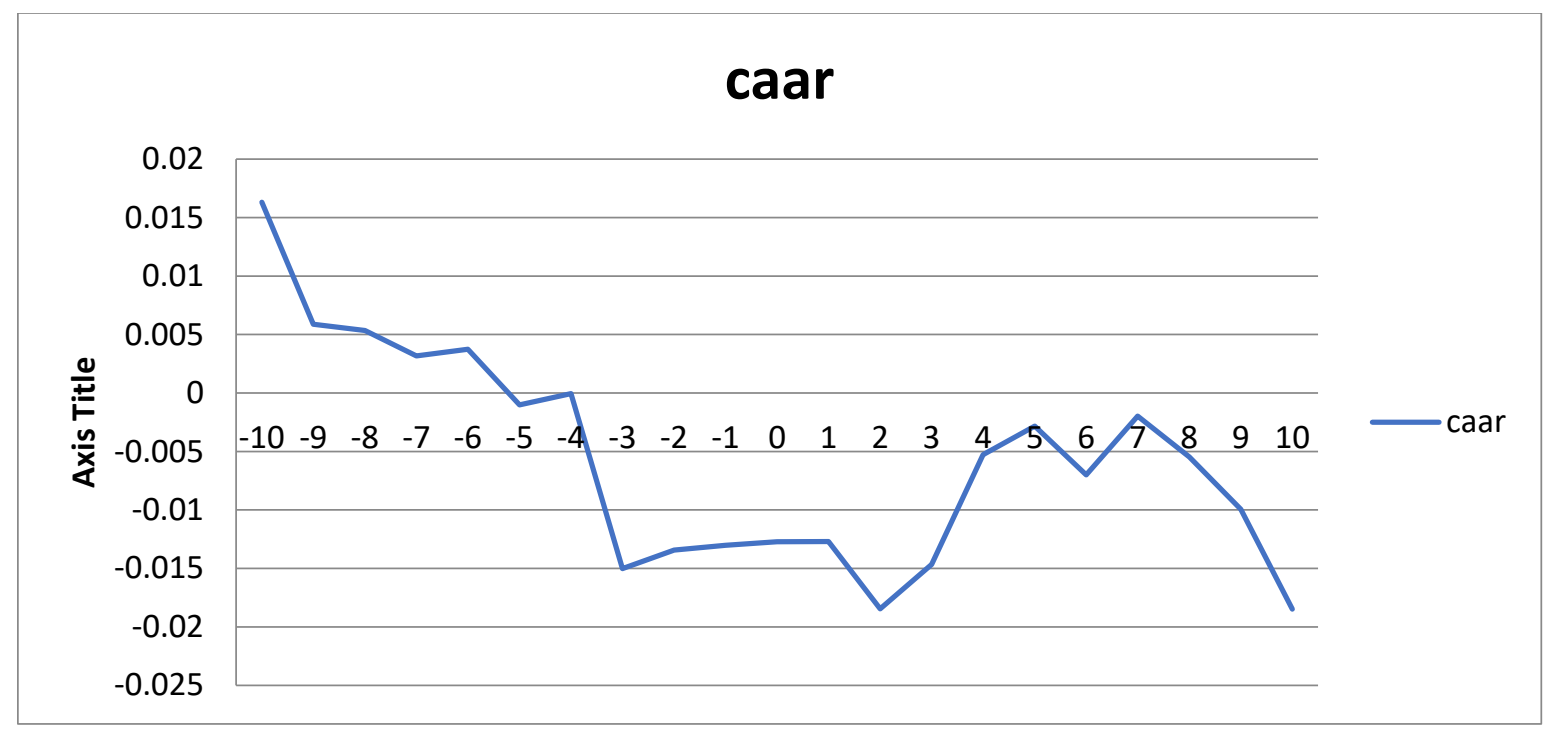

In event of earth quack the caar going down, the graph show that before event cement sale is high and after event the growth of return will be down so this portion is effect by earth quack.

Frame 4: Extreme Temperature.

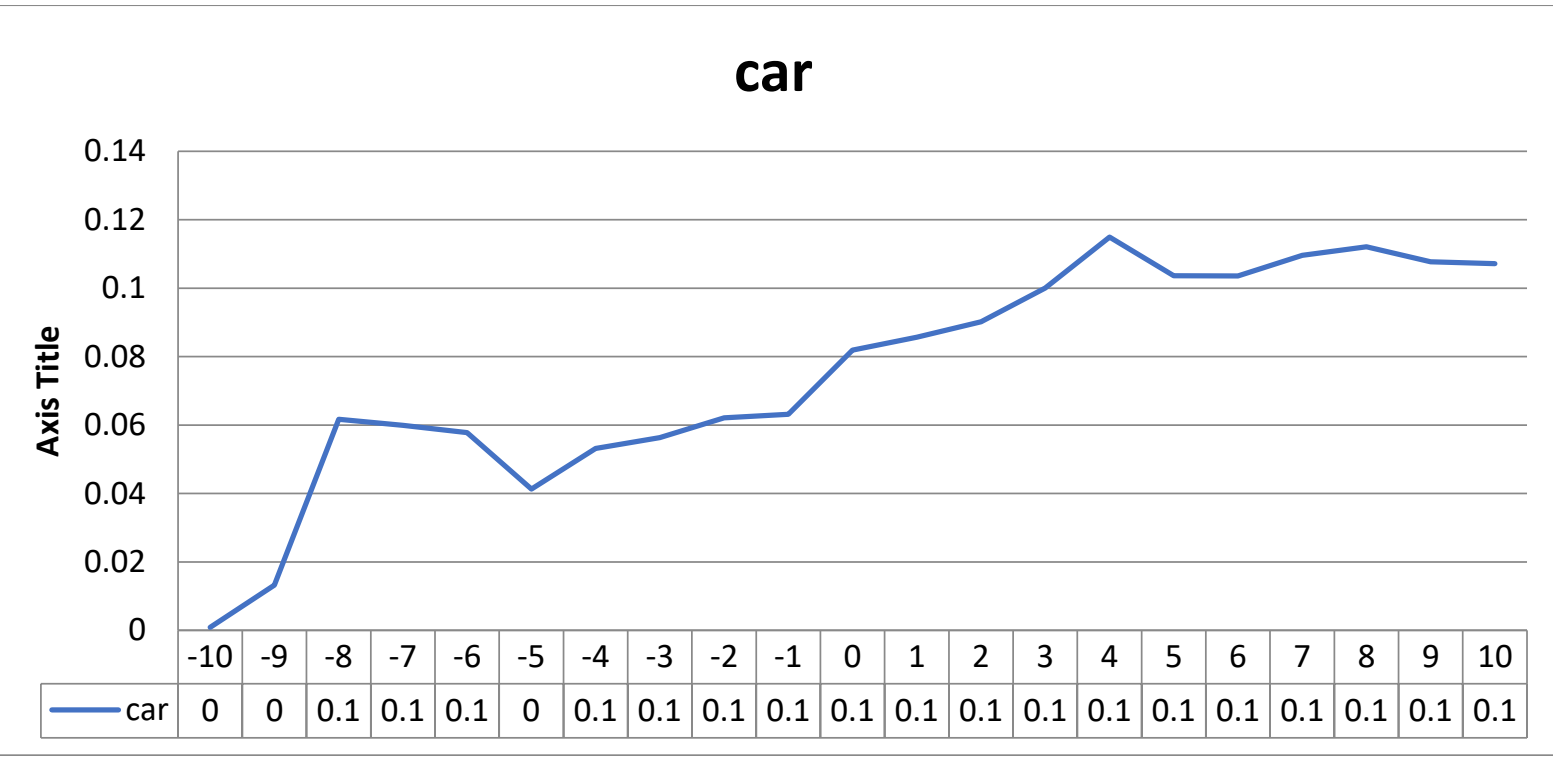

Extreme temperature does not affect the cement sector returns this event show positive trends of returns. Extreme temperature cannot decrease the return of cement sector. Over analysis graph show the positive trends.

Table 1: Average t-stat and averages of abnormal return

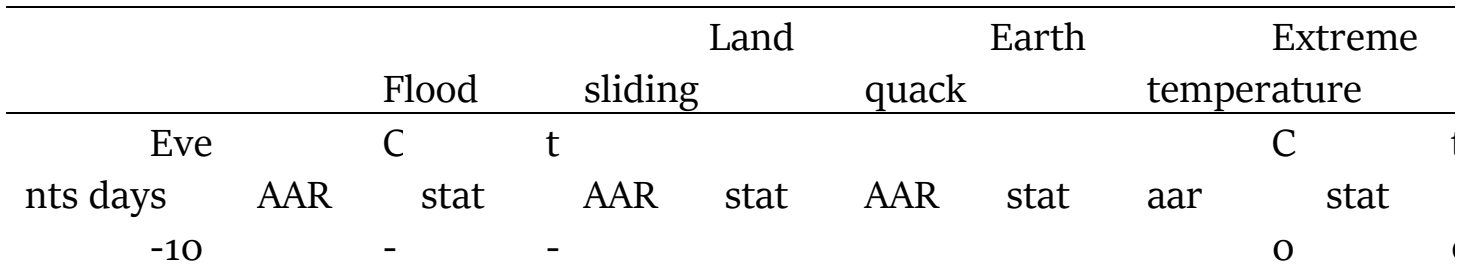




\begin{tabular}{|c|c|c|c|c|c|c|c|c|}
\hline & 0.0103 & 0.3051 & 0.005 & 0.078 & .016 & .666 & .0009 & .013 \\
\hline-9 & 0.0201 & 0.3460 & 0.002 & .087 & .006 & 0.337 & .0132 & .526 \\
\hline-8 & 0.0231 & 0.0845 & .016 & .641 & .005 & 0.316 & $0.062^{* *}$ & .215 \\
\hline & 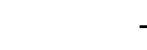 & - & & & & & 0 & \\
\hline-7 & 0.0256 & 0.0532 & 0.003 & 0.134 & .003 & 0.022 & .0599 & 0.185 \\
\hline-6 & 0.0282 & 0.0009 & 0.018 & 0.397 & .004 & 0.012 & .0578 & 0.241 \\
\hline-5 & 0.0395 & 0.5582 & .001 & .560 & 0.001 & 0.206 & .0413 & 0.791 \\
\hline-4 & 0.0458 & 0.2999 & .021 & .408 & .000 & 0.104 & .0532 & .533 \\
\hline-3 & 0.0557 & 0.4830 & .006 & 0.411 & 0.015 & 0.598 & .0563 & .119 \\
\hline-2 & 0.0568 & 0.1458 & 0.001 & .042 & 0.013 & 0.063 & .0621 & .244 \\
\hline-1 & 0.0684 & 0.3759 & .068 & .241 & 0.013 & 0.082 & .0631 & 0.099 \\
\hline $\mathrm{O}$ & 0.0784 & 0.4252 & .118 & .007 & 0.013 & .048 & .0819 & .612 \\
\hline 1 & 0.0840 & 0.2021 & .129 & .250 & 0.013 & .023 & .0857 & .171 \\
\hline 2 & 0.0948 & 0.4387 & .148 & .413 & 0.018 & 0.172 & .0902 & .142 \\
\hline 3 & 0.1027 & 0.3044 & .222 & .232 & 0.015 & 0.110 & .1000 & .429 \\
\hline 4 & 0.1104 & 0.3724 & .226 & 0.325 & 0.005 & .219 & .1149 & .642 \\
\hline 5 & 0.1219 & 0.4862 & .163 & 1.132 & 0.003 & .006 & .1036 & 0.499 \\
\hline 6 & 0.1280 & 0.3696 & .191 & .732 & 0.007 & 0.187 & .1036 & 0.053 \\
\hline 7 & 0.1392 & 0.4756 & .196 & .213 & 0.002 & .192 & 1096 & .167 \\
\hline 8 & 0.1490 & 0.4053 & .192 & .164 & 0.005 & 0.175 & .1121 & .149 \\
\hline 9 & 0.1513 & 0.3114 & .180 & 0.117 & 0.010 & 0.288 & .1077 & 0.251 \\
\hline 10 & 0.1514 & 0.0423 & .153 & 0.409 & 0.018 & 0.223 & .1072 & .149 \\
\hline
\end{tabular}

This table shows the result of event study in flood trend is negative before event the value is .068 and after event going more negative side and the ending value is -.1514. caar value show the negative value in table 1 and the $t$ stat values al show the negative and insignificant effect on flood, last value of $t$ stat is -.0423 , we set the parameter \pm 2.96 , if value on 2.96 then the result show significant so according to this parameter all values is insignificant. Second event is land sliding before event that 
shows the negative caar values -.411 after this value event is occur and after event values going positive side. Mean event effect to return of cement sector these effects is positive, positive trend end on .153 values after 10 days of event. And t stat have no significant value, all value is insignificant bus some value are negative and some are positive $t$ stat according to our parameter of tstat we check not any one figure greater from \pm 2.96 . third event is earth quack, before this event value is positive after event values going down negative so here event have negative effect of return of cement sector prices, starting value of caar is .016 after event ending value is -.018 and tstat have all values are insignificant, last event who discuss in our paper is extreme temperature cannot effect of return of cement sector because caar value increasing continuously trend show positive value in same and the ending value is .1072 and tstat before event have significant one value $0.062^{* *}$ but this value dose not effect because this value before event after event all values show insignificant result .

\section{Conclusion}

This study presents an analysis of impact of natural disaster events on the Pakistani stock markets. We use event study method for analysis. The most important result of this study is that the stocks provided by natural disaster have an influence on markets returns or effect to stocks markets. All other things being equal, earth quack, flood, extreme temperature, lands sliding all have influence on stock markets prices and returns. But those events are rare happening in Pakistan and those events are badly effect to all markets. We are analysis before the event and after the event days of occurrence.

Of course there is several ways in which this work is could be extended. One way is to take greater account of the fact that the financial impact of natural events or disasters will clearly vary according to their precise economic impact. In this manner a focus on a smaller number of major disasters and catastrophes may indicate more significant financial influence. That markets are less liquid markets, as in USA, Austrailia, you will find the ability to impact upon major global Economics. Finally, while it is now the case that better forecasting and emergency management is helping to investor about those adverse effects of some natural disaster events.

\section{Reference}

Albala-Bertrand, J. M. (1993). Natural disaster situations and growth: A macroeconomic model for sudden disaster impacts. World Development, 21, 1417-1434.

Brounen, D. and Derwall, J. 2010. “The Impact of Terrorist Attacks on International Stock

Markets”, European Financial Management, Vol. 16, No. 4, pp. 585-598

Cutler, D. M., Poterba, J. M., \& Summers, L. H. (1989). What moves stock prices? Journal of Portfolio Management , 15 (03), 8-12.

Christian Julliard and Anisha Ghosh. Can rare events explain the equity premium puzzle? Review of Financial Studies, 25(10):3037-3076, 2012.

Cavallo, E. And I. Noy. 2011. "Natural Disasters and the Economy. A Survey." International Review of Environment and Resource Economics 5 (1): 63-102.

Chen, A.H and Siems, T.F. 2004. "The effect of terrorism on global capital markets",

European Journal of Political Economy, Vol.20, No. 2, pp. 349-366.।

David Backus,MikhailChernov, and ianmartin. Disasters implied by equity index options. The Journal of Finance, 66(6):1969-2012, 2011.

Emi Nakamura, Jon Steinsson, Robert Barro, and Jose Ursua. Crises and recoveries in an empirical model of consumption disasters. American Economic Journal: Macroeconomics, 5(3): 35-74, 2013 
Fair, R. C. (2002). Events that shook the market. Journal of Business , 75 (4).

Fomby, T., Y. Ikeda, and N. V. Loayza. 2013. "The Growth Aftermath of Natural Disasters." Journal of Applied Econometrics 28 (3): 312-434.

Kim, k.-h. (2003). Dollar exchange rate and stock price: Evidence from multivariate cointegration and error correction model. Review of Financial Economics , 301-313.

Kothari, S.P. and Warner, J.B. 2007. "Econometrics of Event Studies”, in B. EspenEckbo

(eds), Handbook of Corporate Finance: Empirical Corporate Finance, Vol. 1. Amsterdam:

Elsevier, pp. 3-32.

Skidmore M. And Toya H. (2002) Do natural disasters promote long-run economic growth?, Economic Inquiry, 40(4), 664-87.

Ramiah, V. 2013. "Effects of the Boxing Day tsunami on the world capital markets". Review of Quantitative Finance and Accounting, Vol. 40, No. 2 pp. 383-401.

Robert J. Barro. Rare disasters and asset markets in the twentieth century. The Quarterly Journal of Economics, 121(3):823-866, 2006. Doi: 10.1162/qjec.121.3.823.

Shelor, R., Anderson, D., \& Cross, M. (1990). The impact of the California earthquake on real estate firms' stock value. Journal of Real Estate Research, 5, 335-340.

Thomas A. Rietz. The equity risk premium: A solution. Journal of Monetary Economics, 22(1): 117-131, July 1988.

Valadkhani, A., \& Worthington, A. (2005). Catastrophic Shocks and Capital markets: A Comparative Analysis by Disaster and Sector. Global Economic Review, 34(3), 331-344 